\title{
India, Urban Sanitation, and the Toilet Challenge
}

\author{
Myles F. Elledge and Marcella McClatchey
}

Much of the world's population is in dire need of improved sanitation, but it remains a neglected priority. The United Nations Millennium Development Goals include a global target of a $75 \%$ improvement in sanitation coverage by 2015 , but with current progress rates, this target is one of the most inaccessible. ${ }^{1}$ Currently, 2.5 billion people do not have access to improved sanitation worldwide, and nearly 1.1 billion resort to open defecation. ${ }^{1}$ Open defecation poses significant health and environmental risks. Each year, 1.5 million children die from diarrheal disease, and in India, diarrhea kills one child per minute. ${ }^{2}$ Open defecation also creates vulnerability, particularly for women and girls who experience a loss of dignity or are exposed to abuse and harassment while defecating in the open. Improper waste management can seriously contaminate important sources of drinking water such as surface and groundwater and discourage tourism and economic development.

India is a prime example of the global sanitation challenge; nearly $60 \%$ of the world's open defecation occurs in India. ${ }^{2}$ Rural sanitation in India has received considerably more attention and funding than urban sanitation, yet the health, environmental, and aesthetic consequences of poor sanitation in urban areas are particularly large, given space constraints and population density. Moreover, although Indian cities have become engines of economic growth, India's prospects for long-term prosperity are hindered by its inability to provide basic services.

A study by the World Bank's Water and Sanitation Program (WSP) ${ }^{3}$ estimated that India's lack of sanitation coverage cost the country the equivalent of $6.4 \%$ of its 2006 gross domestic product. Growing poverty and income inequality in urban areas have compounded the sanitation problem, and many Indian mega-cities have very large slum populations. In Mumbai, India's largest city, $57 \%$ of the city's population lives in slums, ${ }^{4}$ and nationally, the 2011 Indian census shows one in six Indians lives in an urban slum. According to the Ministry of Urban Development (MoUD), in notified slums (slums registered by the municipality), $17 \%$ of the population is without access to improved sanitation, and in non-notified slums, the average is $51 \% .{ }^{5}$

\section{The Sanitation Challenge}

- More than $40 \%$ of the world's population lacks improved sanitation facilities, and India's urban sanitation coverage rate is only $50 \%$.

- Consequences of poor sanitation are devastating on human health and the environment.

- Many urban areas provide access to toilets, yet often upkeep is lacking, septage is not well managed, and sewerage is discharged untreated.

Where sanitation access is available, many urban residents use toilets that are not connected to underground sewerage networks. It is estimated that $75-80 \%$ of water pollution by volume is from domestic sewerage. ${ }^{6}$ Only 160 out of nearly 8,000 towns have both sewerage systems and a sewage treatment plant, and only $13 \%$ of piped sewerage is currently treated. ${ }^{7}$ Additionally, treatment capacity is highly uneven, with $40 \%$ of India's total treatment capacity located in just two cities-Delhi and Mumbai.7 Even when there are sewerage networks, much of the waste fails to reach wastewater treatment plants. ${ }^{8}$

Improved sanitation and hygiene is an essential element of strategies to reduce diarrheal disease. Yet closing the gap to universal sanitation coverage is a major challenge. Geographic and demographic constraints in today's urban settings make using conventional sewerage infrastructure investments technically challenging and financially infeasible. Simpler technologies can be less expensive, but they are often physically unattractive, retain odors, and provide suboptimal sludge management solutions.

In slums, space constraints make it difficult to install individual household toilets and build the requisite infrastructure. Community dynamics are often less cohesive than in rural areas, and confused or insecure land tenure rights make it difficult to change behaviors, assign and collect tariffs for communal toilets, or build expensive permanent structures. 


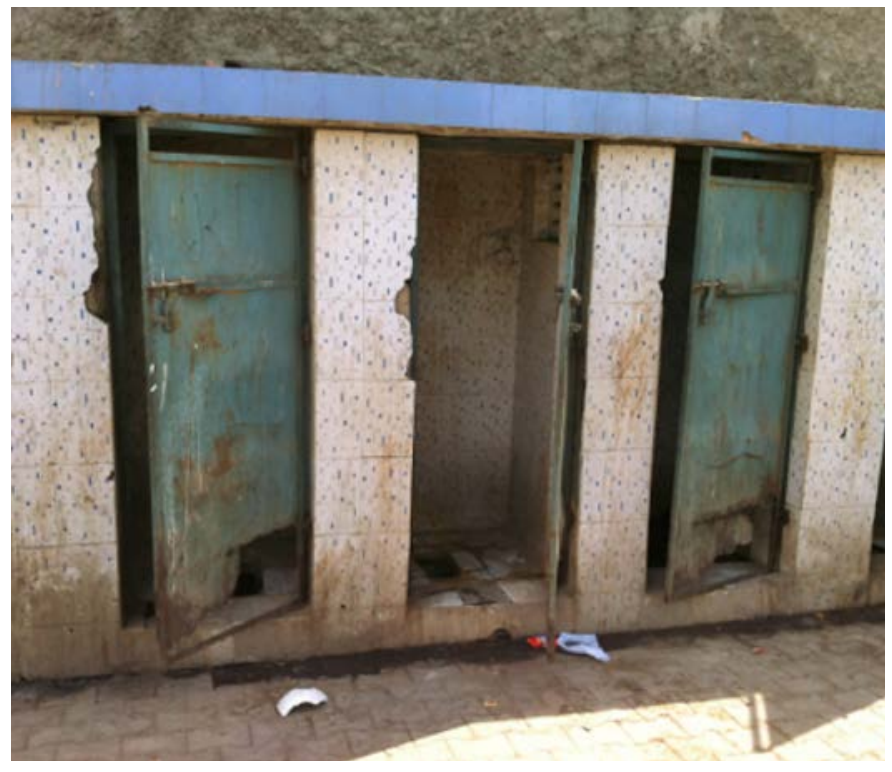

A public block toilet facility in a low-income area of Ahmedabad. Poor maintenance leads to open defecation around the facility.

\section{In Search of New Solutions}

In this context, the sanitation technology paradigm is under review. The Bill and Melinda Gates Foundation stimulated this review with its launch of the Reinvent the Toilet Challenge (RTTC) in 2011 promoting the development of radically new innovations to address the sanitation challenge on a large scale. The RTTC is focused on reinventing the flush toilet, a breakthrough public health invention that has not changed substantially since the first flush toilet patent was issued in 1775. The Foundation has called on grantees to design a standalone toilet unit with no piped-in water, sewer connection, or outside electricity, with facility costs targeted at less than five cents per person per day. The Foundation's sanitation strategy in 2013 focuses on urban areas, and India is one of the priority countries.

The RTTC comes at a time of growing awareness within the Indian government of the dire need for sanitation reform. India's MoUD launched a comprehensive policy on urban sanitation in 2008 (the National Urban Sanitation Policy [NUSP]) designed to address the sanitation problem and anticipate the country's growing needs. Foremost, the NUSP calls attention to urban sanitation by noting that it is distinct from rural sanitation and water supply issues. This is crucial because many actors have traditionally devoted insufficient resources to the urban dimensions of the sanitation problem. ${ }^{5}$ The NUSP sets out goals to increase awareness of India's urban sanitation issue, calls for all cities to be open-defecation-free, and promotes comprehensive approaches to sanitation reform. Under the NUSP, the central government is also responsible for providing technical assistance and helping to fund sanitation plans through schemes such as the Jawaharlal Nehru Urban Renewal Mission, which has dedicated funds for urban development. ${ }^{9}$

Other national programming provides alternative funding options for water supply and sanitation projects. For example, the Rajiv Awas Yojana initiative was launched in 2012 to bring urban slums under formal city management, thus improving prospects for urban service provision, although many implementation hurdles remain. ${ }^{10}$

One strong element of India's current sanitation policy is how it is differentiated from previous government initiatives by its focus on service delivery provision and outcome metrics. The NUSP established a nationwide rating system, and cities will be eligible for a national award when they have made measurable improvements. ${ }^{11}$ The national government has also instituted service-level benchmarks as a way to shift the focus in sanitation from infrastructure to service delivery. 12 The work of the Performance Assessment System Project implemented by CEPT University, Ahmedabad, is taking these benchmarks further to develop improved water and sanitation metrics in the two states of Maharashtra and Gujarat. These national developments are major steps forward-sound sanitation policies are critical to creating an environment that enables increased access to sanitation services, and national policies can serve as a key stimulus for local action, especially in countries such as India that are highly decentralized. ${ }^{13}$

Such forward-thinking national policies provide municipalities with exciting opportunities to innovate, but thus far the gap between these policies and funding and capacity at the decentralized level has slowed progress. Per the Constitution of India, sanitation is primarily the responsibility of urban local bodies, which are the fundamental administrative units in charge of infrastructure and service provision at the municipal level.

The NUSP encourages states to draft state sanitation plans and cities to draft city sanitation plans that are in accordance with the NUSP and uniquely tailored to local contexts. The development of local plans is intended to strengthen the financial, technical, and human capacities within local governments and encourage a more pro-poor focus. Additionally, the NUSP is technology-neutral, which allows cities to choose the most appropriate technology for their needs. In principal, this approach encourages experimentation with technologies and service provision to determine the best local models for improving sanitation quality and expanding access. As of 2012, 29 out of 35 states are engaged in preparing state sanitation plans, and 158 cities are developing city sanitation plans. ${ }^{2}$

However, there is a growing recognition that these plans are highly uneven in their quality, and there is a significant gap in 
funding and execution of the subnational plans. Despite these positive plans, many stakeholders note that the NUSP has fallen short of driving investment into municipal-level plans to enable their execution. More guidance and funding are needed to ensure consistency and quality of state- and citylevel sanitation reform. As of May 2013, national government leadership reports that potential high-impact policies on urban sanitation are now being debated in the parliament, and if passed, they could drive a game-changing new mandate for urban programming that promotes innovation to address sanitation coverage (Elledge, M., interview with an official at the Ministry of Housing and Urban Poverty Alleviation, 21 May 2013).

\section{Options and Models}

India's extreme need for urban sanitation, combined with the decentralized nature of current policy developments, makes the country a particularly conducive place to experiment with innovations in sanitation technology and management. External funding sources are also looking to stimulate innovative sanitation solutions with enterprising cities. Although the private sector has not traditionally played an active role in sanitation, the advent of the NUSP and the increased attention from external stakeholders are gradually encouraging the private sector to become more involved. The WSP estimates that the Indian sanitation market will be valued at over US\$152 billion (between 2007 and 2020), 3 representing a significant business opportunity for innovators and service providers. This convergence of interests presents India with a unique opportunity to stimulate change, and makes India a particularly good place to pilot the Foundation's reinvent-thetoilet technology.

A number of new models are worth noting. One example originating in the State of Kerala illustrates that private sector innovation is piloting new solutions. Eram Scientific Solutions (http://www.eramscientific.com) is a private sector firm driving a new technological and business model to deliver sanitation in congested public places in India's mega-cities. Eram's eToilet is a pay-per-use model now being deployed in four states, with over 430 units installed. The technological features of the toilet include automatic payment collection, doors, and washing mechanisms; a water tank for onsite water storage; general packet radio service (GPRS)-enabled controls for remote monitoring of the unit through the Web or mobile phones; and a solar panel to generate additional power. The toilet is designed to display advertisements on its outer shell, serving as an additional source of income.

Other developments are also unfolding to spur demand and generate new enterprises to provide sanitation services.
The nonprofit organization Water for People (http://www. waterforpeople.org/full-site.html) is implementing a "sanitation as a business" model for household and community toilets and is investing in building entrepreneurial capacity in the sanitation sector. The program also aims to strengthen the sanitation supply chain and develop sanitation providers that offer an increased array of choices in technology options.

Similar smaller scale pilots for providing public sanitation are occurring in many parts of India, bringing a community or commercial approach to operation and maintenance, with sales of advertising space or storefront outlets selling goods to help underwrite the toilet facilities. Other programming is applying stakeholder design consultations to test and enhance features and business models for public toilets, such as the work of the design firm Quicksand in Orissa. RTI International, an RTTC grantee, is looking to field test its standalone toilet in India in 2013.

These initiatives are a welcome addition to the sanitation landscape, but in order for these models to be successful, they will need capable champions within the municipalities. The municipalities, in turn, need to develop a clear understanding of how these innovations fit into the larger goal of comprehensive citywide sanitation. Moreover, although many organizations are working on one or more facets of the problem, strong partnerships are needed to enhance the effectiveness of these models and allow them to meet a wider range of consumer demands, as well as user needs and preferences.

\section{Conclusion}

Globally, inadequate urban sanitation is a significant problem that we can address with innovative programming. India's urban sanitation needs are acute and, if left unmet, carry major consequences for the country and its people. Investing in sanitation is highly cost-effective. The World Health Organization notes that improved sanitation delivers $\$ 9$ in social and economic benefits for every $\$ 1$ invested because it

\section{Key Research \& Policy Recommendations}

- Urban sanitation remains under-studied. More applied work is required to evaluate promising programs and address policy implementation weaknesses.

- Supporting technology development, as well as designing and testing culturally appropriate strategies, is critical to closing India's sanitation gap.

- Programs need to be evaluated with rigorous methods, weak policies need to be strengthened, and sanitation implemented, breaking down bureaucratic barriers to finance and management. 
increases productivity, reduces health care costs, and prevents illness, disability, and early death.

Although the sanitation challenges in India are particularly complex, several developments in sanitation policy and awareness have recently converged, presenting an opportunity to create large-scale change in the sanitation sector. Addressing the urban sanitation challenge requires both new technology and new management approaches, such as those now being tested. Moving forward, it will be important to explicitly connect India's sanitation policies to technological innovations to close the urban sanitation gap.

\section{References}

1. United Nations. The Millennium Development Goals Report 2012. New York: United Nations; 2012 [cited 2013 Jun 30]. Available from http://www.un.org/millenniumgoals/pdf/MDG\%20 Report\%202012.pdf

2. Dasra. Squatting rights: access to toilets in urban India. Mumbai, India: Dasra; 2012 Sep [cited 2013 Jun 30]. Available from http:// www.dasra.org/pdf/SquattingRights_Report.pdf

3. Water and Sanitation Program. Economic impacts of inadequate sanitation in India (flagship report for the World Bank). New Delhi: World Bank; 2011 [cited 2013 Jun 30]. Available from: http://www.wsp.org/sites/wsp.org/files/publications/WSP-esiindia.pdf

4. Performance Assessment System (PAS) Project. Workshop report: innovations for scaling up to citywide sanitation, Ahmedabad, India, 2012 Oct 16-17; Ahmedabad: PAS Project, CEPT University; 2013 [cited 2013 Jun 30]. Available from: http://www.pas.org.in/ Portal/document/ResourcesFiles/pdfs/Report_Sanitation\%20 Workshop.pdf

5. Ministry of Urban Development (MoUD). National urban sanitation policy. New Delhi: MoUD, Government of India; 2008 [cited 2013 Jun 30]. Available from: http://www.urbanindia.nic.in/ programme/uwss/NUSP.pdf

6. Central Pollution Control Board. FAQs. What are sources of water pollution and wastewater generation scenario? Delhi, India: CPCB, Ministry of Environment and Forests, Government of India [cited 2013 Jun 30]. Available from: http://www.cpcb.nic.in/faq1.php\#4

7. Central Pollution Control Board. Status of water supply, wastewater generation and treatment in Class-I cities and Class-II towns of India. Control of Urban Pollution Series: CUPS/70 12009-10). Delhi, India: CPCB, Ministry of Environment and Forests, Government of India; 2009. Retrieved June 30, 2013 from http://www.cpcb.nic.in/upload/NewItems/NewItem_153_ Foreword.pdf
8. Banerjee S, Narain S, Centre for Science and the Environment, Pandey P. Excreta matters: how urban India is soaking up water, polluting rivers, and drowning in its own excreta. New Delhi: Centre for Science and the Environment; 2012.

9. Water Supply \& Sanitation Collaborative Council (WSSCC). Global forum on sanitation and hygiene: highlights of the forum; 2011 Oct 9-14; Mumbai, India. Geneva: WSSCC; 2011 [cited 2013 Jun 30]. Available from http://www.wsscc.org/sites/default/files/ publications/mumbai_highlights_en_17112011.pdf

10. Ministry of Housing and Urban Poverty Alleviation. Rajiv Awas Yojana ... towards a slum-free India: guidelines. New Delhi: Ministry of Housing and Urban and Poverty Alleviation, Government of India; 2011 [cited 2013 Jun 30]. Available from: http://mhupa.gov.in/ray/02-RAY-Guidelines.pdf

11. Ministry of Urban Development (MoUD). National rating and award scheme for sanitation for Indian cities. New Delhi: MoUD, Government of India; 2009 [cited 2013 Jun 30]. Available from: https://www.wsp.org/sites/wsp.org/files/publications/WSP_ NUSP_Flyer.pdf

12. Ministry of Urban Development (MoUD). Improving urban services through service level benchmarking. New Delhi: MoUD, Government of India; 2010 [cited 2013 Jun 30]. Available from: http://www.urbanindia.nic.in/programme/uwss/slb/Flyer.pdf

13. Elledge M, Rosenweig F, Warner DB (with Austin JH, Perez EA). Guidelines for the assessment of national sanitation policies. Strategic Report 2. Washington, DC: United States Agency for International Development; 2002 [cited 2013 Jun 30]. Supported by the Environmental Health Project. Available from: http://www. ehproject.org/PDF/Strategic_papers/SRSanPolFinal.pdf

\section{About the Authors}

Myles F. Elledge, MPIA (Master's in Public and International Affairs), is a senior director in RTI's International Development Group.

At the time of writing, Marcella McClatchey, MPP (Master's in Public Policy), was a graduate student at Duke University and a policy research intern at RTI International.

RTI Press Research Briefs and Policy Briefs are scholarly essays on policy, methods, or other topics relevant to RTI areas of research or technical focus.

RTI International, 3040 East Cornwallis Road, PO Box 12194 Research Triangle Park, NC 27709-2194 USA

919.541.6000_rtipress@rti.org_www.rti.org

C2013 Research Triangle Institute. RTI International is a registered trademark and a trade name of Research Triangle Institute. The RTI logo is a registered trademark of Research Triangle Institute.

(c) (i) (-) $\Theta$ This work is distributed under the terms of a Creative Commons (C) Attribution-NonCommercial-NoDerivatives 4.0 license (CC BY-NC-ND), a copy of which is available at https://creativecommons.org/ licenses/by-nc-nd/4.0/legalcoder.

RTI Press publication RB-0006-1213

doi:10.3768/rtipress.2013.rb.0006.1213

www.rti.org/rtipress 